\title{
THE PRINCIPLE OF RECOGNITION OF MARRIAGE CONCLUDED IN THE REGISTRY OFFICE: THE PROBLEMS OF THEORY AND PRACTICE
}

\author{
Anatoly Ya. Ryzhenkov \\ Volgograd State University, Volgograd, Russian Federation
}

\begin{abstract}
Introduction: the principles of law are the core of any branch of law, defining the vector of its development and helping to fill in the legal loopholes identified in the course of law enforcement activities. The study of the principles of law is necessary because the unambiguousness and justification (in terms of the legal drafting methodology) of their formulation depends on the efficiency of their implementation, determined by the norms of the relevant industry affiliation. Family law in this sense is not an exception, and one of its least studied principles is the principle of recognition of marriage concluded in the registry office. The article aims to investigate the mechanism of implementing the principle of recognition of marriage concluded in the registry office. Methods: the methodological framework for this study is a set of methods of scientific knowledge, among which the main ones are the methods of system analysis, historicism and the comparative law method. Results: the paper considers the modern problems of implementing the principle of recognition of marriage in the registry office, as well as studies the concept and content of such categories as "legal status", "marriage" and "acts of civil status", presents the ways of improving the legal mechanism to register marriages in the registry office, identifies the main goal and public interest in creating a system of registration of marriages, namely, by the registry office, and not by the religious organizations. Conclusions: the paper substantiates that the processes of globalization, as well as the development of technology, computer science and medicine will constantly set the legislator the task of adopting new family law norms, and the vector of such an activity should be determined by the family law principles. Therefore, the formulation of the principle of marriage registration as a special legal status in the registry office requires further discussion, taking into account these modern realities. Thus, it appears that under the current legislation, and the historical traditions in Russia it is inappropriate to consider marriage as a treaty or agreement, since its legal regulation is more inclined to constitutional law, rather than to civil law, focusing not so much on property as on personal non-property rights of spouses, relationships with children and etc. So the concept of marriage as a voluntary union of a man and a woman is more convincing.
\end{abstract}

Key words: principles, marriage, state, registration, legal fact, family relationship, spouse, terminology.

Citation. Ryzhenkov A.Ya. The Principle of Recognition of Marriage Concluded in the Registry Office: The Problems of Theory and Practice. Legal Concept, 2020, vol. 19, no. 1, pp. 92-101. (in Russian). DOI: https://doi.org/ 10.15688/lc.jvolsu.2020.1.13

\section{ПРИНЦИП ПРИЗНАНИЯ БРАКА, ЗАКЛЮЧЕННОГО В ОРГАНАХ ЗАГС: ПРОБЛЕМЫ ТЕОРИИ И ПРАКТИКИ}

\author{
Анатолий Яковлевич Рыженков \\ Волгоградский государственный университет, г. Волгоград, Российская Федерация
}

Введение: принципы права являются ядром любой отрасли права, определяя вектор ее развития и помогая восполнять пробелы, выявляемые в ходе правоприменительной деятельности. Исследование принципов права необходимо потому, что от точности и оправданности (с точки зрения юридической техники) их формулировки зависит эффективность их реализации, определяемая нормами соответствующей отраслевой 
принадлежности. Семейное право в этом смысле не является исключением, а одним из наименее исследованных его принципов является принцип признания брака, заключенного в органах ЗАГС. В статье поставлена цель - исследовать механизм реализации принципа признания брака, заключенного в органах ЗАГС. Методы: методологическую основу данного исследования составляет совокупность методов научного познания, среди которых основное место занимают методы системного анализа, историзма и сравнительноправовой метод. Результаты: в статье рассмотрены современные проблемы реализации принципа признания брака, заключенного в органах ЗАГС, в том числе исследовано понятие и содержание категорий «правовое состояние», «брак», а также «акты гражданского состояния», показаны пути совершенствования правового механизма регистрации браков органами ЗАГС, выявлена основная цель и государственный интерес в создании системы регистрации браков именно органами ЗАГС, а не религиозными организациями. Выводы: в статье обосновывается, что процессы глобализации, а также развития техники, информатики и медицины будут постоянно ставить перед законодателем задачу принятия новых семейно-правовых норм, а вектор такой деятельности должны определять семейно-правовые принципы. Поэтому формулировка принципа регистрации брака как особого правового состояния в органах ЗАГС требует дальнейшего обсуждения с учетом этих современных реалий. При этом представляется, что брак в рамках действующего сегодня законодательства и исторических традиций в России нецелесообразно рассматривать как договор или соглашение, поскольку его правовое регулирование больше тяготеет не к гражданскому, а конституционному праву, акцентируя внимание не столько на имущественных, сколько на личных неимущественных правах супругов, их взаимоотношениях с детьми и т. д. Поэтому концепция брака как добровольного союза мужчины и женщины более убедительна.

Ключевые слова: принципы, брак, состояние, регистрация, юридический факт, семейное правоотношение, супруг, терминология.

Цитирование. Рыженков А. Я. Принцип признания брака, заключенного в органах ЗАГС: проблемы теории и практики // Legal Concept = Правовая парадигма. - 2020. - T. 19, № 1. - C. 92-101. - DOI: https://doi.org/10.15688/lc.jvolsu.2020.1.13

\section{Введение}

Принципы права являются ядром любой отрасли права, определяя вектор ее развития и помогая восполнять пробелы, выявляемые в ходе правоприменительной деятельности. Исследование принципов права необходимо потому, что от точности и оправданности (с точки зрения юридической техники) их формулировки зависит эффективность их реализации, определяемая нормами соответствующей отраслевой принадлежности. Семейное право в этом смысле не является исключением, а одним из наименее исследованных его принципов является принцип признания брака, заключенного в органах ЗАГС.

Включение данного принципа в ст. 1 СК РФ имеет определенную историческую обусловленность. Первоначально в Российской империи предусматривался церковный брак. Государственная (светская) регистрация брака органами публичной власти была нормативно введена только после Октябрьской революции 1917 г., когда был принят специальный декрет ВЦИК и СНК РСФСР от 18 декабря 1917 г. «О гражданском браке, о детях и о ведении книг актов гражданского состояния». Этим декретом отменялась церковная форма брака и ее признавали впредь частным делом лиц, вступающих в брак. При этом какое-то время после революции регистрация брака вообще не считалась императивно обязательной. Как отмечал Я.Н. Бранденбургский, «регистрация - пережиток, со временем она, конечно, исчезнет, но сейчас она сохраняется, главным образом, как средство борьбы с церковным браком» [2, с. 6].

Ситуация стала меняться только после принятия в 1926 г. Кодекса законов о браке, семье и опеке РСФСР. Однако несмотря на насаждение гражданской (светской) регистрации браков, в СССР продолжали признаваться действительными религиозные браки, заключенные до Октябрьской революции 1917 года. В настоящий момент аналогичное исключение предусмотрено п. 7 ст. 169 СК РФ, согласно которому нормы о признании правовой силы только за браком, государственная регистрация заключения которого осуществлена в органах ЗАГС, не применяется к бракам граждан Российской Федерации, совершенным по религиозным обрядам на оккупи- 
рованных территориях, входивших в состав СССР в период Великой Отечественной войны, до восстановления на этих территориях органов записи актов гражданского состояния.

Кроме того, следует заметить, что во многих странах регистрация брака сейчас производится в религиозной форме. Поэтому брак, заключенный в такой форме гражданином РФ в государстве, где это предусмотрено законом (Англия, Кипр, Лихтенштейн), будет действительным на территории России.

В России механизм реализации исследуемого принципа предусмотрен как нормами самого СК РФ (гл. 3), так и гл. 3 Федерального закона от 15.11.1997 № 143-Ф3 (ред. от 01.10.2019) «Об актах гражданского состояния», которая называется «Государственная регистрация заключения брака».

\section{Механизм реализации принципа признания брака, заключенного в органах ЗАГС}

Исследование механизма реализации принципа признания брака, заключенного в органах ЗАГС, предполагает ответы на следующие вопросы:

1) что такое «состояние» как правовая категория, подлежащая регистрации в органах ЗАГС? Что такое «акты гражданского состояния»? Что такое брак и в чем специфика брака как разновидности правовых состояний?

2) какова цель и государственный интерес в создании системы регистрации брака именно органами ЗАГС, а не религиозными организациями?

Попробуем последовательно ответить на поставленные вопросы.

1. Общая теория права подразделяет юридические факты по характеру их действия на факты однократного и непрерывного действия (состояния). Юридические факты-состояния действуют длительный срок, порождая все это время определенные юридические последствия. Типичным примером таких фактов является гражданство или инвалидность. Юридическая природа фактов-состояний до конца не определена, и потому одни авторы относят их к категории действий, а другие считают их особой категорией юри- дических фактов. Последнее утверждение, на наш взгляд, заслуживает поддержки.

Следует согласиться с мнением, что юридический факт-состояние - «это конкретное жизненное обстоятельство, характеризующееся относительной стабильностью и длительным периодом существования, в течение которого самостоятельно или в совокупности с другими юридическими фактами вызывающее правовые последствия и не погашающееся в единократном акте правового воздействия» [7, с. 6]. Это определение вполне уместно и для брака.

Как отмечает Е.А. Храпунова, «состояние в браке не может быть сведено всего лишь к длящемуся правоотношению, так как оно имеет юридическое значение не только для лиц, вступивших в брак, но и для иных субъектов права, и не может быть сведено по своему юридическому значению только к совокупности прав и обязанностей супругов по отношению друг к другу. Поэтому состоянию как разновидности юридического факта давно следует предоставить место в традиционной системе юридических фактов для упорядочения регулирования правоотношений, возникающих, прежде всего, в сфере регулирования гражданского и семейного права, которая весьма нуждается в этом на настоящий момент» [17, с. 80-81]. Таким образом, юридические факты-состояния (включая брак) являются самостоятельной разновидностью юридических фактов, характеризующейся признаками длительности и неоднократности наступления семейных, гражданских и иных правовых последствий.

Многие правовые состояния подлежат государственной регистрации. Применительно к браку такая регистрация осуществляется органами записи актов гражданского состояния (ЗАГС). Включение в ГК РФ и СК РФ норм о государственной регистрации актов гражданского состояния (то есть императивных, административных норм) является типичным примером взаимного проникновения норм различной отраслевой принадлежности. Если рассматривать акт регистрации в рамках других классификаций юридических фактов (например, их подразделения на правообразующие, правоизменяющие и правопрекращающие), то регистрация брака - это 
«правоизменяющий юридический факт, направленный на возникновение нового юридического статуса - состояния супружества, и, соответственно, новых субъектов семейных правоотношений - супругов» [5, с. 25]. Впрочем, большинство актов гражданского состояния (например, развод) носят такой же характер, прекращая одни и образуя другие правовые состояния граждан, изменяя их по сути. Представляется, что акты гражданского состояния - это имеющие место в действительности обстоятельства, влекущие юридические последствия, перечисленные в законе, и подлежащие государственной регистрации в установленном порядке.

Данное определение представляется более точным, чем нормативно закрепленное: «акты гражданского состояния - действия граждан или события, влияющие на возникновение, изменение или прекращение прав и обязанностей, а также характеризующие правовое состояние граждан» (ст. 3 Федерального закона от 15.11.1997 № 143-Ф3 «Об актах гражданского состояния»).

Данный вывод основан на том, что, вопервых, официальное определение «актов гражданского состояния» раскрывает данный термин упоминанием «правового состояния граждан», что не совсем удачно с точки зрения юридической техники. Во-вторых, далеко не все «действия граждан или события» перечислены в законе и требуют государственной регистрации.

В рамках темы настоящей статьи следует заметить, что брак относится к числу правовых состояний граждан, требующих государственной регистрации. При этом в научной литературе все еще нет единого понимания того, что следует называть «браком». Причиной таких дискуссий является отсутствие в СК РФ (в отличие от многих других законов и кодексов) специальной статьи, раскрывающей официальное толкование семейно-правовой терминологии.

Сегодня во многих странах мира (например, в Исламской Республике Афганистан) ученые предлагают следующее определение брака: «брак - это сделка в виде правомерных действий лиц, вступающих в брак, и их опекунов, направленная на установление, изменение или прекращение имущественных и личных неимущественных прав и обязанностей у брачующихся» $[10$, с. 6$]$.

По мнению И.А. Трофимец, «брак - это договор мужчины и женщины, достигших брачного возраста, основанный на чувствах взаимной любви и уважения, зарегистрированный в органах записи актов гражданского состояния, при отсутствии препятствующих браку обстоятельств, порождающий правоотношения супружества, как личного, так и имущественного характера, заключаемый бессрочно с целью создания семьи (совместного проживания, ведения общего хозяйства, рождения и воспитания детей)» $[15$, с. 8]. Аналогичным образом, С.В. Сивохина полагает, что под браком «понимается требующее государственной регистрации соглашение мужчины и женщины, направленное на создание и поддержание правовых брачно-семейных отношений в рамках брачного союза, предусмотренного законом» $[14$, с. 8$]$.

Между тем наряду с концепцией «брака-соглашения (сделки, договора)» в научной литературе высказываются и другие точки зрения, рассматривающие брак не как договор, а как добровольный и равноправный союз.

Так, Н.В. Орлова предлагала понимать брак как «добровольный и равноправный союз мужчины и женщины, заключаемый с соблюдением условий и порядка, предусмотренных законом, направленный на создание семьи и порождающий личные и имущественные права и обязанности супругов» [9, с. 19]. В свою очередь, А.М. Нечаева полагала, что «брак представляет собою союз женщины и мужчины, заключаемый в принципе пожизненно с целью создания семьи» [6, с. 5]. По мнению В.А. Рясенцева, брак - это заключаемый в установленном порядке с соблюдением требований закона добровольный и равноправный в принципе пожизненный союз свободных мужчины и женщины, направленный на создание семьи и порождающий у них взаимные права и обязанности» [12, с. 67]. Представляется, что брак в рамках действующего сегодня законодательства и исторических традиций в России нецелесообразно рассматривать как договор (соглашение), поскольку его правовое регулирование больше тяготеет не к гражданскому, а конституционному праву, ак- 
центируя внимание не столько на имущественных, сколько на личных неимущественных правах супругов, их взаимоотношениях с детьми и т. д. Поэтому концепция брака как добровольного союза мужчины и женщины представляется более убедительной.

Из указанного подхода вытекают следующие признаки брака как правового состояния, регистрацию которого предусматривает исследуемый принцип: брак - это союз мужчины и женщины (что исключает возможность однополых браков); брак - это добровольный и равноправный союз; брак - это союз, приобретающий юридическое значение только после его государственной регистрации.

Представляется, что с точки зрения реализации исследуемого принципа, следует различать состояние в зарегистрированном браке, и состояние в фактическом браке. Последняя категория выходит за рамки исследуемого принципа, и не признается государством, хотя и является популярной у современной молодежи. По большому счету, это состояние аналогично официальному браку, однако не находится под правовой защитой государства, является фиктивным. При этом даже в странах, где закон закрепляет «законное совместное проживание» (как в Бельгии), предусматривающее для таких субъектов ряд прав и социальных льгот, оно все равно не уравнено полностью с классическим институтом брака [4, с. 12].

2. Отвечая на второй вопрос, следует заметить, что государственная регистрация актов гражданского состояния устанавливается в целях охраны имущественных и личных неимущественных прав граждан, а также в интересах государства. Государственная регистрация акта гражданского состояния производится органом записи актов гражданского состояния посредством составления в Едином государственном реестре записей актов гражданского состояния соответствующей записи акта гражданского состояния, на основании которой выдается свидетельство о государственной регистрации акта гражданского состояния. Являясь официальным доказательством зарегистрированных фактов, они сохраняют это значение, пока не будут изменены или аннулированы. При этом сама регистрация актов гражданского состояния не играет правообразующего значения, поскольку она лишь подтверждает наличие определенных юридических фактов. Исключением является лишь регистрация заключения брака, без которой брака нет. В этом случае регистрируется не факт, имевший место, а, напротив, сама регистрация порождает данный факт.

Государственный интерес в регистрации брака (по большому счету, частного дела граждан) заключается в том, что органы государственной власти осуществляют контроль за соблюдением гражданами условий действительности брака (например, препятствуя тем самым многоженству). Оформляя частные отношения мужчины и женщины, государство создает условия стабильности существования семьи и воспитания детей, предусматривает отдельные социальные гарантии для членов семьи, получает важные статистические сведения о количестве семей, которые используются при разработке основных направлений семейной и демографической политики России. Таким образом, исследуемый принцип лежит в основе не только достижения гражданами личных целей, но и эффективности государственной семейной политики.

В рамках обсуждения этого вопроса следует упомянуть предложение С.В. Сивохиной о том, что для обеспечения публичности заключения браков следует «восстановить институт свидетелей бракосочетания и внести в Закон РФ “Об актах гражданского состояния” норму, обязывающую органы записи актов гражданского состояния вывешивать в помещениях соответствующих органов ЗАГСа списки лиц, подавших заявление с просьбой о регистрации брака» [14, с. 10]. Поставленная автором проблема заключается в том, где проходят границы между частными и публичными интересами, и каковы должны быть пределы вмешательства органов публичной власти в частную жизнь граждан? Представляется, что введение таких дополнительных требований нарушит конституционную норму о праве на неприкосновенность частной жизни, личную и семейную тайну (ст. 23) и едва ли что-то добавит к целям и задачам государства, поэтому такое вмешательство было бы избыточным. 


\section{Современные проблемы реализации принципа признания брака, заключенного в органах ЗАГС}

Несмотря на достаточно развернутый механизм реализации исследуемого принципа, следует отметить здесь наличие ряда дискуссионных проблем.

1. Согласно ст. 158 СК РФ браки между гражданами Российской Федерации и браки между гражданами Российской Федерации и иностранными гражданами или лицами без гражданства, заключенные за пределами территории Российской Федерации с соблюдением законодательства государства, на территории которого они заключены, признаются действительными в Российской Федерации, если отсутствуют предусмотренные ст. 14 СК РФ обстоятельства, препятствующие заключению брака. В числе таких обстоятельств указанная статья выделяет недопустимость заключения брака между лицами, из которых хотя бы одно уже состоит в другом зарегистрированном браке. В этом случае возникает следующий вопрос: если гражданка Российской Федерации выйдет замуж в мусульманской стране (где допустимо многоженство), то будет ли это порождать правовые последствия в России? Разумеется, вступить в подобный брак в России нельзя, однако закон не дает четких указаний о том, могут ли возникать алиментные обязательства, вытекающие из такого брака?

2. Нормы СК РФ, предусматривающие, что брак есть добровольный союз мужчины и женщины, тем самым запрещают однополые браки. Однако несмотря на такой запрет, в судебной практике есть случаи, когда граждане пытались обжаловать в суде отказ в регистрации такого брака. В частности, по одному из таких дел Липецкий областной суд указал, что согласно ст. 9 Хартии основных прав Европейского союза от 12 декабря 2007 г. право на вступление в брак и право на создание семьи гарантируются в соответствии с национальным законодательством, регламентирующим его осуществление. В силу правовой позиции, изложенной Европейским судом по правам человека в Постановлении от 24 июня 2010 г. «Шальк и Копф против Австрии», вопрос о разрешении или запрещении од- нополых браков регулируется национальным законодательством. Статья 12 Конвенции не обязывает государства разрешать однополым парам вступление в брак. Согласно ст. 12 СК РФ для заключения брака необходимы взаимное добровольное согласие мужчины и женщины, вступающих в брак, и достижение ими брачного возраста. В силу правовой позиции, изложенной в Определении Конституционного Суда РФ от 16 ноября 2006 г. № 496-О «Об отказе в принятии к рассмотрению жалобы гражданина Э. Мурзина на нарушение его конституционных прав пунктом 1 статьи 12 Семейного Кодекса Российской Федерации», одно из предназначений семьи - это рождение и воспитание детей. Таким образом, законодательством России не предусмотрена возможность регистрации брака между лицами одного пола.

Иной подход ряда европейских государств, допускающий заключение однополых браков, не может влиять на государственную политику России в области семейных отношений, основные начала которой базируются на принципе противоположности полов лиц, вступающих в брак, исходящим из отношения к браку как биологическому союзу только мужчины и женщины [1].

3. В научной литературе в качестве неустранимого (грубого, существенного) нарушения процедуры регистрации брака признается отсутствие в зале регистрации одной из сторон (брачующихся). В этом случае нарушается принцип одновременного личного общения вступающих в брак с представителем компетентного государственного органа, регистрирующего брак [16, с. 101].

Между тем в XXI в. все чаще возникают ситуации, немыслимые ранее, которые часто ставят в тупик правоприменителя, порождая вопрос о необходимости совершенствования семейного законодательства в части процедуры регистрации брака в органах ЗАГС. Так, 10 августа 2003 г. впервые в истории состоялась регистрация космической свадьбы. Бракосочетание было заочным: в момент заключения брака российский космонавт Юрий Маланченко пребывал на орбите, а его невеста - американка российского происхождения Екатерина Дмитриева - на Земле. Таким образом, жених присутствовал на 
церемонии виртуально, вместо него в свидетельстве о браке расписался его адвокат. При этом примечательно, что разрешение на брак Екатерина Дмитриева получила беспрепятственно: по законам штата Техас (США) жених или невеста могут отсутствовать на свадьбе. При этом идея «космической свадьбы» была полной неожиданностью для российских властей, но она состоялась [11].

Подобного рода истории, несомненно, носят единичный характер, однако в обычной земной жизни проблема заочного присутствия жениха или невесты в органах ЗАГС при регистрации брака возникает достаточно часто, и потому требует дополнительного обсуждения. Дело в том, что в последние годы многие аспекты жизни граждан и государства переместились в Интернет. Разрешены электронные подписи и электронное голосование. В ноябре 2016 г. бывший президент Украины В. Янукович даже давал показания в режиме видеосвязи Киевскому суду, находясь при этом в Ростовской области [18]. Однако возможность заключения брака с использованием интернет-технологий не предусмотрена ст. 11 СК РФ, настаивающей на личном присутствии брачующихся в органе ЗАГС. Представляется, что в данном случае есть место для дискуссий, которые позволят приблизить правила СК к техническим реалиям XXI века.

4. Как отмечает Е.Ю. Горская, до сих пор «закон при совершении юридически значимых действий, например, при внесении изменений при перемене пола гражданином, ссылается на подзаконные акты, которые должны быть установлены федеральным органом исполнительной власти, осуществляющим функции по выработке и реализации государственной политики и нормативно-правовому регулированию в сфере здравоохранения, однако до настоящего времени не утвержденные. Это затрудняет реализацию прав и интересов граждан и делает процедуру юридической смены пола волокитной и длительной. Отсутствие своевременного регулирования новых по своему содержанию возникающих отношений приводит не только к нарушениям прав граждан, но и, в связи со спецификой рассматриваемых правоотношений, к семейным трагедиям» [3, с. 6]. Из этого вытекает еще одна проблема реализации исследуемого принципа: при перемене пола членами семьи могут стать лица одного пола, что запрещает ст. 12 СК РФ. Однако процедуры принудительного расторжения такого брака не предусмотрены, и этот вопрос остается открытым.

5. Как отмечает И.А. Трофимец, существует «тенденция к фактическому расширению полигамии в обществах, основанных на моногамии (Россия и государства Средней Азии - бывшие республики СССР). В России с учетом реально сложившейся ситуации представляется допустимой полигамия, как форма (модель) брака, при соблюдении определенных требований: наличия материальных возможностей мужчины содержать своих жен и детей; а также согласия каждой из женщин» [15, с. 9]. Стоит отметить, что идея многоженства (и обязательности регистрации в ЗАГСе таких браков) является весьма востребованной не только в теории, но и на практике. Так, Законом Республики Ингушетия «О регулировании некоторых вопросов семейно-брачных отношений в Республике Ингушетия», принятым Народным Собранием-Парламентом Республики Ингушетия 31 июля 1999 г., была предусмотрена возможность заключения гражданами мужского пола до четырех браков с лицами женского пола, не состоящими в браке (ст. 2). Рассматривая дело о признании данной статьи недействующей, Верховный Суд РФ указал, что согласно ст. 76 Конституции РФ законы и иные нормативные правовые акты субъектов РФ, принятые по предметам совместного ведения, не могут противоречить федеральным законам. Установив противоречие норм обжалуемого Закона Республики Ингушетия федеральному законодательству, суд обоснованно признал данные нормы недействующими и не подлежащими применению [8].

Идея многоженства, имеющая определенную популярность в РФ, тем не менее расходится с действующим законодательством, а также нравственными воззрениями большинства населения страны, не поддерживающего данное предложение и придерживающегося традиционных представлений о браке.

6. В последнее время все чаще учеными и депутатами Государственной Думы поднимается вопрос о возможности приравнять процедуру венчания в церкви с регистрацией 
брака в органах ЗАГС. В качестве аргументов упоминается необходимость разгрузить ЗАГСы, возврат к традициям, нерациональность двойной регистрации брака (в церкви и ЗАГС), в том числе по финансовым причинам [13, с. 170-171]. Между тем реализация данного предложения прямо противоречит ст. 14 Конституции Российской Федерации, провозглашающей Россию светским государством, а, кроме того, создаст проблемы с ведением Единого государственного реестра записей актов гражданского состояния, поскольку в этом процессе будут участвовать православные христиане, мусульмане, буддисты, а также представители иных религиозных концессий.

\section{Выводы}

Таким образом, процессы глобализации, а также развития техники, информатики и медицины будут ставить перед законодателем необходимость принятия новых семейно-правовых норм, а вектор такой деятельности должны определять семейно-правовые принципы. Поэтому формулировка принципа регистрации брака как особого правового состояния в органах ЗАГС требует дальнейшего обсуждения с учетом этих современных реалий.

При этом представляется, что брак в рамках действующего сегодня законодательства и исторических традиций в России нецелесообразно рассматривать как договор или соглашение, поскольку его правовое регулирование больше тяготеет не к гражданскому, а конституционному праву, акцентируя внимание не столько на имущественных, сколько на личных неимущественных правах супругов, их взаимоотношениях с детьми и т. д. Поэтому концепция брака как добровольного союза мужчины и женщины представляется более убедительной.

\section{СПИСОК ЛИТЕРАТУРЫ}

1. Апелляционное определение Липецкого областного суда от 07.10.2013 по делу № 33-2656/ 2013. - Доступ из справ.-правовой системы «КонсультантПлюс» (дата обращения: 28.11.2019).

2. Бранденбургский, Я. Н. Брак и его правовые последствия / Я. Н. Бранденбургский. - М. : Юрид. изд-во НКЮ РСФСР, 1926. - 37 с.
3. Горская, Е. Ю. Акты гражданского состояния как основания возникновения, изменения и прекращения гражданских и семейных правоотношений : автореф. дис. ... канд. юрид. наук / Горская Екатерина Юрьевна. - М., 2015. - 29 с.

4. Дородонова, Н. В. Правовое регулирование брачных отношений в Бельгии: вопросы истории и современные проблемы : автореф. дис. ... канд. юрид. наук / Дородонова Наталия Васильевна. - Саратов, 2009. $-27 \mathrm{c}$.

5. Наумов, Я. В. Условия и порядок заключения брака в российском семейном праве : автореф. дис. ... канд. юрид. наук / Наумов Ярослав Васильевич. - М., 2017. -28 c.

6. Нечаева, А. М. Правонарушения в личных семейных отношениях / А. М. Нечаева. - М. : Наука, 1991.-238 с.

7. Новикова, Ю. С. Правовое состояние как категория права : автореф. дис. ... канд. юрид. наук / Новикова Юлия Сергеевна. - Екатеринбург, 2005. $-24 \mathrm{c}$.

8. Определение Верховного Суда РФ от 18 сентября 2000 г. по делу № 26-ГОО-5. - Электрон. текстовые дан. - Режим доступа: http://sudbiblioteka.ru/ vs/text_big1/verhsud_big_8298.htm (дата обращения: 28.11.2019). - Загл. с экрана.

9. Орлова, Н. В. Правовое регулирование брака в СССР / Н. В. Орлова. - М. : Наука, 1971. - 127 с.

10. Пайкан, С. Правовое регулирование бракосочетания в Исламской Республике Афганистан : автореф. дис. ... канд. юрид. наук / Пайкан Сурая. Душанбе, 2010. -25 c.

11. Первая космическая свадьба едва не стоила космонавту карьеры. - Электрон. текстовые дан. - Режим доступа: https://ria.ru/20080810/ 150249971.html (дата обращения: 27.11.2019). - Загл. с экрана.

12. Рясенцев, В. А. Семейное право / В. А. Рясенцев. - М. : Юрид. лит., 1971. -296 с.

13. Серова, О. А. Брак как акт гражданского состояния / О. А. Серова // Теоретические и практические проблемы государственной регистрации актов гражданского состояния. - Тверь : Издатель А.Н. Кондратьев, 2017. - С. 169-172.

14. Сивохина, С. В. Понятие брака и условия его действительности в современном праве России и Франции : автореф. дис. ... канд. юрид. наук / Сивохина Светлана Владимировна. - М., 2006. - 24 с.

15. Трофимец, И. А. Институт брака в России, государствах-участниках Содружества Независимых Государств и Балтии : автореф. дис. ... д-ра юрид. наук / Трофимец Ирина Александровна. Хабаровск, 2011. $-47 \mathrm{c}$.

16. Фетисова, О. В. Соотношение понятий недействительный и несостоявшийся брак / О. В. Фетисова // Современное право. - 2009. - № 10. - С. 99-102. 
17. Храпунова, Е. А. К вопросу места состояний в системе юридических фактов, влекущих возникновение, изменение и прекращение гражданских правоотношений / Е. А. Храпунова // Наука и образование: хозяйство и экономика; предпринимательство; право и управление. - 2012. - № 2. C. $79-82$.

18. Янукович дает показания киевскому суду. Дистанционно. - Электрон. текстовые дан. - Режим доступа: https://www.5-tv.ru/news/112605/ (дата обращения: 27.11.2019). - Загл. с экрана.

\section{REFERENCES}

1. Apellyatsionnoye opredeleniye Lipetskogo oblastnogo suda ot 07.10.2013 po delu № 33-2656/2013 [Appellate Determination of the Lipetsk Regional Court of 07.10.2013 in Case no. 33-2656/2013]. Access from Reference Legal System "ConsultantPlus" (accessed 28 November 2019).

2. Brandenburgskiy Ya.N. Brak i ego pravovyye posledstviya [Marriage and its Legal Consequences]. Moscow, Yurid. izd-vo NKYu RSFSR, 1926. 37 p.

3. Gorskaya E.Yu. Akty grazhdanskogo sostoyaniya kak osnovaniya vozniknoveniya, izmeneniya $i$ prekrashcheniya grazhdanskikh $i$ semeynykh pravootnosheniy: avtoref. dis. ... kand. yurid. nauk [Acts ofCivil Status as the Basis for the Emergence, Change and Termination of Civil and Family Relations. Cand. jurid. sci. abs. diss.]. Moscow, 2015.29 p.

4. Dorodonova N.V. Pravovoye regulirovaniye brachnykh otnosheniy $v$ Belgii: voprosy istorii $i$ sovremennyye problemy: avtoref. dis. ... kand. yurid. nauk [The Legal Regulation of Marital Relations in Belgium: Questions of Hstory and Modern Problems. Cand. jurid. sci. abs. diss.]. Saratov, 2009. 27 p.

5. Naumov Ya.V. Usloviya i poryadok zaklyucheniya braka $v$ rossiyskom semeynom prave: avtoref. dis. ... kand. yurid. nauk [Conditions and Procedure of Marriage in Russian Family Law. Cand. jurid. sci. abs. diss.]. Moscow, 2017. 28 p.

6. Nechayeva A.M. Pravonarusheniya $v$ lichnykh semeynykh otnosheniyakh [Offense in Personal Family Relations]. Moscow, Nauka Publ., 1991. $238 \mathrm{p}$.

7. Novikova Yu.S. Pravovoye sostoyaniye kak kategoriya prava: avtoref. dis. ... kand. yurid. nauk [Legal Status as a Category of Law. Cand. jurid. sci. abs. diss.]. Yekaterinburg, 2005. 24 p.

8. Opredeleniye Verkhovnogo Suda RF ot 18 sentyabrya $2000 \mathrm{~g}$. po delu № 26-GOO-5 [Determination of the Supreme Court of the Russian Federation of September 18, 2000 in Case No. 26-goo-5]. URL: http://sudbiblioteka.ru/vs/text_big1/verhsud_ big_8298.htm (accessed 28 November 2019).
9. Orlova N.V. Pravovoye regulirovaniye braka $v$ SSSR [Legal Regulation of Marriage in the USSR]. Moscow, Nauka Publ., 1971. 127 p.

10. Paykan S. Pravovoye regulirovaniye brakosochetaniya $v$ Islamskoy Respublike Afganistan: avtoref. dis. ... kand. yurid. nauk [Legal Regulation of Marriage in the Islamic Republic of Afghanistan. Cand. jurid. sci. abs. diss.]. Dushanbe, 2010.25 p.

11. Pervaya kosmicheskaya svadba edva ne stoila kosmonavtu karyery [The First Space Wedding Almost Cost the Astronaut Career]. URL: https://ria.ru/ 20080810/150249971.html (accessed 27 November 2019).

12. Ryasentsev V.A. Semeynoye pravo [Family Law]. Moscow, Legal literature, 1971.296 p.

13. Serova O.A. Brak kak akt grazhdanskogo sostoyaniya [Marriage as an Act of Civil Status]. Teoreticheskiye $i$ prakticheskiye problemy gosudarstvennoy registratsii aktov grazhdanskogo sostoyaniya [Theoretical and Practical Problems of State Registration of Acts of Civil Status]. Tver, Publisher A.N. Kondratiev, 2017, pp. 169-172.

14. Sivokhina S.V. Ponyatiye braka i usloviya ego deystvitelnosti $v$ sovremennom prave Rossii $i$ Frantsii: avtoref. dis. ... kand. yurid. nauk [Concept of Marriage and the Conditions of its Validity in the Modern Law of Russia and France. Cand. jurid. sci. abs. diss.]. Moscow, 2006. 24 p.

15. Trofimets I.A. Institut braka $v$ Rossii. gosudarstvakh-uchastnikakh Sodruzhestva Nezavisimykh Gosudarstv i Baltii: avtoref. dis. ... dra yurid. nauk [The Institution of Marriage in Russia, the Member States of the Commonwealth of Independent States and the Baltic States. Dr. jurid. sci. abs. diss.]. Khabarovsk, 2011. 47 p.

16. Fetisova O.V. Sootnosheniye ponyatiy nedeystvitelnyy i nesostoyavshiysya brak [Correlation of Concepts Invalid and Failed Marriage]. Sovremennoye pravo [Modern law], 2009, no. 10, pp. 99-102.

17. Khrapunova E.A. K voprosu mesta sostoyaniy $\mathrm{v}$ sisteme yuridicheskikh faktov, vlekushchikh vozniknoveniye, izmeneniye i prekrashcheniye grazhdanskikh pravootnosheniy [On the Question of the Place of States in the System of Legal Facts, Entailing the Emergence, Change and Termination of Civil Relations]. Nauka i obrazovaniye: khozyaystvo i ekonomika; predprinimatelstvo; pravo $i$ upravleniye [Science and Education: Economy and Economics; Entrepreneurship; Law and Management], 2012, no. 2, pp. 79-82.

18. Yanukovich dayet pokazaniya kiyevskomu sudu. Distantsionno [Yanukovych Testifies to the Kiev Court]. URL: https://www.5-tv.ru/news/112605/ (accessed 27 November 2019). 
А.Я. Рыюженков. Принцип признания брака, заключенного в органах ЗАГС: проблемы теории и практики

\section{Information About the Author}

Anatoly Ya. Ryzhenkov, Doctor of Sciences (Jurisprudence), Professor, Department of Civil and Private International Law, Base Department of the Southern Scientific Centre of the Russian Academy of Sciences, Volgograd State University, Prosp. Universitetsky, 100, 400062 Volgograd, Russian Federation, 407778@list.ru, https://orcid.org/0000-0002-2015-1709

\section{Информация об авторе}

Анатолий Яковлевич Рыженков, доктор юридических наук, профессор кафедры гражданского и международного частного права (базовая кафедра ЮНЦ РАН), Волгоградский государственный университет, просп. Университетский, 100, 400062 г. Волгоград, Российская Федерация, 407778@list.ru, https://orcid.org/0000-0002-2015-1709 